\title{
Spontaneous formation and degradation of pool-riffle morphology and sediment sorting using a simple fractional transport model
}

\author{
Gustavo Adolfo Mazza de Almeida ${ }^{1}$ and José F. Rodríguez ${ }^{2,3}$ \\ Received 23 January 2012; revised 29 February 2012; accepted 1 March 2012; published 28 March 2012.
}

[1] Many gravel bed streams have a typical bed morphology consisting of pool-riffle sequences, which provides important habitat diversity both in terms of flow and substrate. A complete explanation of pool-riffle genesis and self-maintenance remains elusive and, despite advances in understanding the effects of flow spatial and temporal variability, the key sediment processes have been only marginally explored. Here we use a 1D unsteady multi-fraction morphodynamic model to explain the formation and degradation of pool-riffle sequences. Using a 1-year time series of measured flows below bankfull on a stream in which we have removed initial bedforms and sediment sorting our model spontaneously generates pools with finer substrate at narrow sections and riffles with coarser sediment at wider sections, closely resembling the natural bed morphology. Additional experiments show that under our modelling assumptions a variable flow regime is fundamental for development and self-maintenance of the longitudinal grain sorting characteristic of pool-riffle sequences, which could not be obtained or maintained with discharges held constant over relatively long periods. Citation: de Almeida, G. A. M., and J. F. Rodríguez (2012), Spontaneous formation and degradation of pool-riffle morphology and sediment sorting using a simple fractional transport model, Geophys. Res. Lett., 39, L06407, doi:10.1029/2012GL051059.

\section{Introduction}

[2] The ubiquity and persistence of pools and riffles in rivers with different slopes and substrate conditions have puzzled geomorphologists for a long time and different explanations have been proposed to understand their genesis and self-maintenance [Keller, 1971; Yang, 1971; Clifford, 1993]. Perhaps one of the most controversial is the velocity reversal hypothesis [Keller, 1971], which was originally based on observations from Seddon [1900] and Gilbert [1914] that low discharges fill pools and erode riffles, while the opposite occurs during high flows. The hypothesis states that the bottom velocity in the pool is less than in the adjacent riffle at low flows, but increases faster with discharge until the situation is reversed for flows above bankfull. Further research demonstrated that reversal conditions were not as common as originally thought, and successive adjustments to the initial hypothesis included 2 and 3-D flow and turbulence effects (e.g., jet flow and separation, secondary circulation,

\footnotetext{
${ }^{1}$ School of Geographical Sciences, University of Bristol, Bristol, UK.

${ }^{2}$ School of Engineering, University of Newcastle Australia, Callaghan, New South Wales, Australia.

${ }^{3}$ eWater CRC, Canberra, ACT, Australia.

Copyright 2012 by the American Geophysical Union. 0094-8276/12/2012GL051059
}

macro-scale turbulent flow structure) that locally produced reversal conditions [Thompson et al., 1996; Booker et al., 2001; MacWilliams et al., 2006; Rhoads et al., 2008; Caamaño et al., 2012; Thompson, 2011, and references therein]. All these alternative explanations have a strong theoretical and observational basis but do not give enough consideration to the continuously varying topography and grain size spatial distribution, even though under reversal conditions the bed is expected to undergo important modifications that interact with the flow.

[3] Understanding how these interactions between dynamic changes in topography and particle sorting affect transport and morphodynamics requires a level of temporal and spatial resolution very difficult to obtain from observations. Although some efforts have been made to measure sediment size distribution and transport characteristics (e.g., entrainment and deposition patterns; suspended and bedload rates) in the field [Thompson et al., 1999; Thompson and Hoffmann, 2001; Thompson and Wohl, 2009], the information typically consists of a few size distributions at specific points before and after one or a sequence of events. Numerical simulations of flow and sediment, on the other hand, can provide detailed information even during high flow events, which can be extremely helpful in explaining some of the sediment-flow feedbacks associated with self maintenance of pools and riffles [de Almeida and Rodríguez, 2011]. de Almeida and Rodríguez [2011] simple 1D numerical model of unsteady flow, fractional sediment transport and bed sorting processes demonstrated that considering not only the effects of the flow but also the influence of sediment being transported and in the bed results in a two-fold increase on the frequency of self-maintenance events. Two main mechanisms contribute to this: differential sediment mobility that produces transport reversal even if no velocity reversal occurs, and drowning of the local riffle crest due to temporary accretion of the downstream riffle that promotes velocity reversal. The continuous tracking of morphology and grainsize distribution during a series of natural discharges allowed for the identification of those key mechanisms.

[4] In this paper we study the formation and long term degradation of the pool-riffle morphology and grain sorting with the same 1D morphodynamic modelling approach used by de Almeida and Rodríguez [2011], and we explore the influence of new mechanisms inherently associated with the dynamics of the system. Previous research (ours included) has focussed almost exclusively on understanding selfmaintenance on existing pool-riffle sequences, leaving formation and degradation at a speculative level. Spontaneous formation of pools and riffles has not been attempted before, even though other similar stable bedforms have been generated numerically and in the laboratory through the interaction of flow and sediment transport, like alternate 
bars in meanders [Tubino and Seminara, 1990] and central bars in braided rivers [Repetto et al., 2002]. While this previous research substantially simplified flow (constant discharge), geometry (sinusoidal description of curvature or channel width) and sediment (uniform material) it showed the forcing effects of either curvature or width on the location of bedforms. For the formation of pools and riffles we use elements of the previous approach (width forcing) but we also incorporate a much more detailed geometry, flow and sediment description, since our intent is to study driving mechanisms for both the morphology and the sediment composition of the bed in a more realistic setting.

[5] We tested three hypotheses using our model. The first hypothesis states that the dynamic interaction of flow and sediment processes simulated with a $1 \mathrm{D}$ numerical model under a regime of variable flows below bankfull and in the presence of width variations can not only maintain but also generate a stable pool-riffle morphology with a characteristic pattern of longitudinal sorting. The second hypothesis states that the pool-riffle morphology and grain sorting can be generated under constant flows of different magnitude. Finally, we test whether the long term action of constant flows can drive a significant degradation of the morphology or longitudinal sorting characteristics of an existing poolriffle sequence even with varying channel width. We performed both variable flow and constant flow simulations imposing the width variations observed in an existing reach. The variable flow formation experiment used one year of natural discharges, during which a pool-riffle sequence developed at the same location and with similar geometric characteristics and longitudinal sorting to that naturally occurring on the reach, confirming our first hypothesis. The particular formative dynamics observed during variable flows was characterized by excess riffle deposition and pool erosion accompanied by suppression of sorting during high flows, followed by restorative riffle erosion and pool deposition together with re-sorting during the falling limb of hydrographs. The constant flow experiments used a series of discharges, in which the erosion/deposition and sorting could be analysed without the simultaneous effect of variable flows both during formation and degradation of a pool-riffle sequence. These experiments showed that the stream adjusts to new flow conditions first by altering grain size, but after some time erosion/deposition processes dominate and sorting is suppressed. The asymptotic long term bed configuration (after 10 years) consists of pools and riffles at the same location as in the variable flow experiments, with a bedform size that depends on the particular discharge and without the typical marked longitudinal sorting. The different response obtained under variable and constant discharges is due to different time scales between erosion/deposition and sediment sorting processes, the later responding faster to flow changes. This finding, which provides a new mechanistic explanation for the maintenance of sorting in pool-riffle sequences, was made possible by the analysis of the detailed model results.

\section{Model Description and Setup}

[6] The numerical model used in this paper is described in detail by de Almeida and Rodríguez [2011], and in Text S1 of the auxiliary material, so only a brief outline will be presented here. ${ }^{1}$ The model combines four individual modules: water flow, fractional sediment transport, morphodynamics and grain sorting. Modules are solved sequentially using short time steps allowing for almost immediate feedback effects. Firstly, a 1-D unsteady flow model computes shear stresses (see auxiliary material for a detailed description), which are used to estimate bed load for individual sediment size fractions. The hydraulic model solves the Saint-Venant equations using a generalized form of the Preissmann scheme, with the friction slope obtained using Manning's equation and a conveyance subdivision method. Sediment transport rates are estimated for individual size fractions using the Wilcock and Crowe [2003] equation, which accounts for differences in mobility through a hiding function and also considers the effect of the sand content on the critical shear stress of bed surface mean size. In order to avoid the underestimation of sediment transport that would result from using cross sectional average values of depth and skin friction, the model uses local values of shear stress on subdivisions of the cross section and then integrates the result. Sediment transport rates are then used to determine bed level changes and update the grain size distribution of the bed. Cross sectional average bed level changes are computed using Exner's equation and then distributed transversely as a function of the local flow depth. Substrate grain size distribution changes are calculated on the basis of the fractional mass conservation of bedload in the active layer [Hirano, 1971], which is continuously shifting vertically depending on whether deposition or erosion takes place. Underneath the active layer, several deeper layers are used to store the grain size history due to previous sediment transport events and become activated as needed. The new bed (both in terms of elevation and roughness composition) is finally fed back into the model to finalize the loop and start a new time step.

[7] The model is by no means comprehensive, as it represents only a small subset of physical mechanisms deemed essential to study the processes investigated in this paper. In this regard, even though a detailed field data set was used as a guide, the study should still be interpreted as an idealized numerical experiment. Although this approach has a restricted direct applicability, it allows the study of relatively complex problems without the confounding influence of other processes inherently present in any real world experiment. In particular, the 1-D formulation disregards complex flow features such as turbulence, flow concentration and separation [Clifford and Richards, 1992; Thompson et al., 1996, 1999], and secondary currents [Booker et al., 2001; MacWilliams et al., 2006], which occur even in straight reaches and may have a strong influence on sediment transport and morphology. Other important phenomena not taken into account include bank lateral migration and failure, flow and sediment interaction with vegetation, particle queuing and changes in soil porosity during bed sorting processes, to name a few.

[8] The geometric and substrate conditions used in the simulations are based on the characteristics of a $1.1 \mathrm{~km}$ long reach of the lower Bear Creek, a gravel-bed tributary of the Buffalo River in Arkansas, USA in which the model has been previously tested and calibrated [de Almeida and Rodríguez, 2011]. The reach has a well-defined sequence of three pool-riffle units and is considerably entrenched.

\footnotetext{
${ }^{1}$ Auxiliary materials are available in the HTML. doi:10.1029/ 2012GL051059.
} 


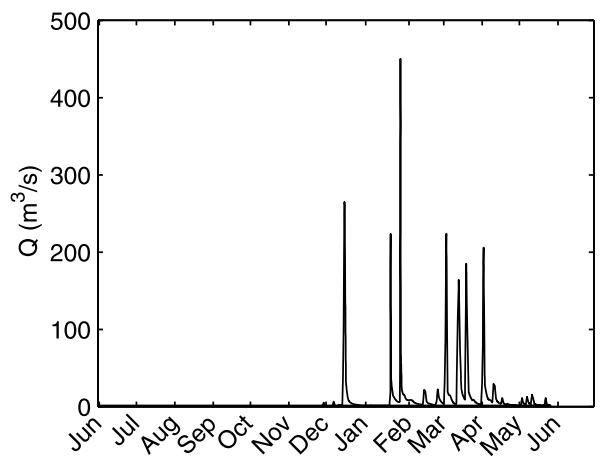

Figure 1. Discharge time series used in the one-year long simulation.

Bankfull depth and width vary from 5 to $7 \mathrm{~m}$ and from 30 to $40 \mathrm{~m}$, respectively and the average reach slope is 0.002 . Bankfull discharge is estimated between 420 and $450 \mathrm{~m}^{3} / \mathrm{s}$, approximately. The grainsize distribution of the material found in the channel varies longitudinally, with reach-averaged values indicating $4.3 \%$ in the sand range $(0.06-2 \mathrm{~mm}), 84 \%$ gravel $(2-64 \mathrm{~mm}), 10.2 \%$ cobble, $1.5 \%$ boulder $(>256 \mathrm{~mm})$, and a $D_{50}$ of $29.5 \mathrm{~mm}$. In order to eliminate local geometric effects and concentrate on more general characteristics, the cross sections were reshaped to a trapezoidal form with right and left reach-average lateral slopes and a base width determined as the hydraulic width for a $2 \mathrm{~m}$ flow depth. This value of base width was obtained by trial and error as the one that best reproduced the general shape of the cross sections (see Text S1 in the auxiliary material). Figure 2 presents two longitudinal profiles of the bed (June 2001 and Feb 2002) as well as the corresponding profile of the base widths used in this paper. More detailed information on the site characteristics is provided by Reuter et al. [2003] and in the auxiliary material.

\section{Numerical Experiments}

\subsection{Pool-Riffle Formation Under Variable Flow Regime}

[9] The first numerical experiment aimed at testing the first hypothesis, i.e., the possibility of modelling the formation of a pool-riffle sequence (both in terms of bed elevations and longitudinal sediment sorting) under a variable flow regime. The stream natural bed topography was replaced by a flat bed with uniform slope of 0.002 and constant granulometry, given by the reach-averaged fractions of each grain size class. The simulation used a one-year series of natural discharges measured between June 2001 and June 2002 (Figure 1), with a relatively dry June-December period (maximum daily mean flow of $10.6 \mathrm{~m}^{3} / \mathrm{s}$ ) but a much more active second half with several important floods, including a $2 \sim 4$ years recurrence interval flood of $460 \mathrm{~m}^{3} / \mathrm{s}$ [Reuter et al., 2003]. At the downstream end of the reach uniform flow conditions were imposed. The sediment supply to the reach (upstream boundary condition) was set as the reach-averaged sediment transport capacity estimated using a fractional sediment transport-discharge curve previously constructed by running a series of constant flows over a frozen natural topography [de Almeida and Rodríguez, 2011]. Uncertainties associated with this estimation can result in generalized trends of erosion or deposition over the reach, which may be important for longer time scales but are not critical for the one-year simulation.

\subsection{Pool-Riffle Formation Under Constant Flow Regime}

[10] Testing the second hypothesis required long term model runs in which sediment processes were allowed to freely interact without the influence of varying discharge. A series of nine constant-flow simulations with discharges ranging from 30 to $250 \mathrm{~m}^{3} / \mathrm{s}$ was carried out, with a duration of 10 years in an attempt to achieve asymptotic equilibrium conditions. The initial bed was flat (i.e., constant longitudinal slope) and unsorted (reach-average sediment distribution). Uniform flow conditions where specified at the downstream end and transport capacity was used as the sediment upstream boundary condition. Preliminary runs indicated that, for these long-term runs, the sediment supply estimation used in the one-year simulations generated changes in the average reach slope superimposed to the patterns of localized bed deformations. In order to suppress this effect, and after extensive testing over a wide range of sediment supply values, the sediment supply was increased by a factor of 1.35 .

(a)
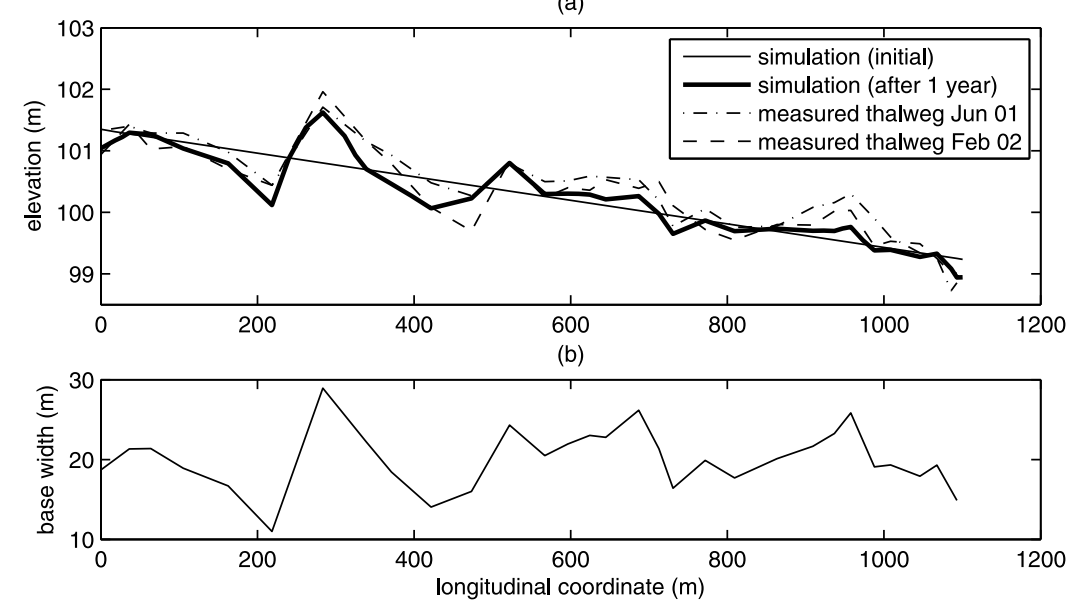

Figure 2. (a) Initial and final bed profile after the one-year continuous simulation and field measurements in June 2001 and February 2002. (b) Cross sections base widths. 


\subsection{Pool-Riffle Degradation}

[11] The pool-riffle degradation experiments tested our third hypothesis. Since degradation is typically linked to streamflow alterations, most of which consist on flow regulation, it was of interest to investigate to what extent constant flows influence an initially undisturbed pool-riffle morphology. The same nine discharges of the constant flow formation experiments were run for 10 years over an initial pool-riffle morphology and longitudinal sorting bed corresponding to the final results obtained after the variable flow run. All other sediment and flow boundary conditions (including sediment supply) were the same as in the steady flow formation experiments.

\subsection{Data Analysis}

[12] The interactions between the different mechanisms represented in the model - some of which operate at different time scales and are nonlinear - render the results analysis considerably complex. In particular, preliminary runs showed a rather erratic evolution of local bed elevations and $D_{50}$ at a given cross section, even under steady boundary conditions. However, when these results were integrated at larger spatial scales (e.g., reach scale) clearer patterns of bed and grain size evolution emerged. In the analysis of the results we have used the root mean square (RMS) of bed variations with respect to the overall reach slope $Z_{R M S}$ and the RMS of mean grain size $\left(D_{50}\right)_{R M S}$ to represent, respectively, the degree of bed elevation and sediment size variation over the reach. These metrics allowed us to study the time evolution of the pool-riffle morphology and longitudinal sorting over the reach. In order to test our hypothesis, the values of these metrics obtained in the constant flow experiments are compared against the variable flow regime and those corresponding to the field data available.

\section{Results}

\subsection{Pool-Riffle Formation Under Variable Flow Regime}

[13] After one year of continuous simulation under a variable flow regime the model produced a longitudinal profile remarkably similar to the observed natural topography, as shown by Figure 2a and Animation S1 in the auxiliary material, confirming our first hypothesis. All riffle crests and pool troughs observed in the reach spontaneously formed during the simulation and the specific bed elevation after one year is within the range of natural variation observed between two successive field measurements. Not only does the simulation capture the essential bed geometry, but the computed bed surface also exhibits the longitudinal sorting observed in natural pool-riffle sequences, with sediment being coarser at the riffles and finer at the pools. $Z_{R M S}$ and $\left(D_{50}\right)_{R M S}$ were calculated from the results of the simulations $\left(Z_{R M S}=0.27\right.$ and $\left.\left(D_{50}\right)_{R M S}=0.46\right)$ and compared favourably with the measured values $\left(Z_{R M S}=0.34\right.$ and $\left.\left(D_{50}\right)_{R M S}=0.49\right)$.

[14] The simulations show that during this relatively short period of time a considerable amount of bed reworking occurred, with some pool sections scouring up to $0.8 \mathrm{~m}$ and riffle sections aggrading up to $1.1 \mathrm{~m}$ (see Animation S1 in the auxiliary material). Riffle deposition and pool erosion with suppression of sorting occurred during high flows (1-year return or more), followed by restorative riffle erosion and pool deposition with strong sorting during the falling limb of hydrographs. The formation of this irregular profile took place without any significant trend of generalized erosion or deposition in the reach, as the overall reach slope was virtually unaffected. Furthermore, the pool-riffle locations were strongly correlated with width variations in the reach (Figure 2b), which highlights the strength of width variations control on the development of the longitudinal profile of the reach.

\subsection{Pool-Riffle Formation Under Constant Flow Regime}

[15] The coupled evolution of topography and bed sediment in terms of $Z_{R M S}$ and $\left(D_{50}\right)_{R M S}$ can be observed in Figure 3 , which also includes $Z_{R M S}$ and $\left(D_{50}\right)_{R M S}$ values obtained from the measurements and those obtained at the end of the variable flow simulation. Figures $3 a$ shows that all constant discharge runs generated asymptotic equilibrium bedforms resembling pool-riffle sequences at the same position as the variable flow run, but only constant discharges between about 75 and $140 \mathrm{~m}^{3} / \mathrm{s}$ produced bedforms with amplitudes comparable to the variable flow run and the measurements. The pool-riffle amplitude was larger for higher flows and smaller for lower flows. However, none of the constant runs displayed a sorting pattern comparable to that of the variable flow run; they all produced a bed with considerably less sorting (Figure $3 \mathrm{~b}$ ). In terms of sediment dynamics, the constant flow experiments showed that the stream adjusts (i.e., reduces high initial transport capacity gradients) to new flow conditions first by altering grain size, but after some time erosion and deposition processes dominate (i.e., reducing shear stress gradients) and, eventually, sorting is almost suppressed.

\subsection{Pool-Riffle Degradation}

[16] Figure 4 presents the results in terms of $Z_{R M S}$ and $\left(D_{50}\right)_{R M S}$ and includes as a reference both the measured values and the values obtained with the variable flow formation experiments (which also corresponds to the initial values for these steady flow runs). Figure $4 \mathrm{a}$ shows that the reach-scale bed geometry evolution described by $Z_{R M S}$ tends towards an equilibrium value that depends on flow discharge, with flows above a certain threshold increasing the differences between pool and riffle elevations and flows below the threshold gradually flattening the reach. As with the formation experiments (Figure 3a), the threshold discharge varies between 75 and $140 \mathrm{~m}^{3} / \mathrm{s}$ and is intimately associated with velocity reversal hypothesis (even though more mechanisms are included in the present modelling approach). The reach longitudinal sorting represented by $\left(D_{50}\right)_{R M S}$ in Figure $4 \mathrm{~b}$ shows some strong initial increases in sorting for the lower discharges but eventually all discharges produce sorting patterns much less pronounced than those observed in the field. Degradation then occurs for all discharges, confirming our third hypothesis.

\section{Discussion}

[17] The pool-riffle formation experiments showed the strong control exerted by the width in forcing the occurrence of riffles at wider sections and pools at narrow points, in accordance with observations [White et al., 2010; Sawyer et al., 2010] and previous modelling results in idealized 
(a)
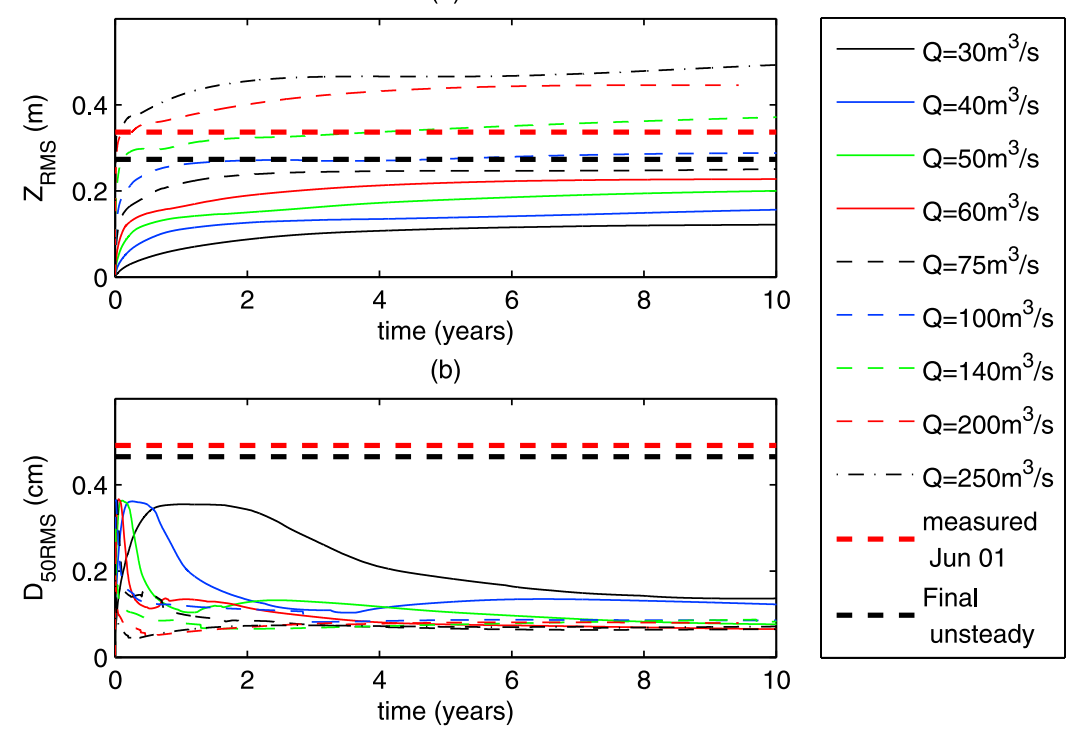

(1)

Figure 3. Time series of (a) $Z_{R M S}$ and (b) $\left(D_{50}\right)_{R M S}$ for different flow discharges for simulations beginning with a flat bed profile. Values corresponding to the bed profile in June 2001 and the final profile obtained in the variable flow simulation are also shown.

conditions [Repetto et al., 2002]. The variable flow formation results presented in Figure 2 and the auxiliary material (Animation S1) not only showed the capability of the model to spontaneously generate the pool-riffle morphology with the corresponding longitudinal sorting, but also helped understand the main mechanisms taking place. A number of feedback effects involving the continuous adaptation of bed form and material ultimately resulted in a resilient system that could accommodate a very wide range of discharges (in our experiment up to a 4-year return period flow) maintaining essentially the same structure.

[18] Bedforms resembling pool-riffle sequences could be generated using a constant discharge at the same locations as in the variable flow experiment. However, longitudinal grain sorting patterns developed during these simulations were considerably less strong than field observations and the results of our numerical experiment with the natural variable flow regime, violating our second hypothesis. An asymptotic degree of bed deformation comparable to the field observations was obtained with constant discharges (i.e., between 75 and $140 \mathrm{~m}^{3} / \mathrm{s}$ ) that were lower than the highest peaks of the variable flow simulations (Figure 3a). Regarding bed sediment composition during formation by constant discharges, Figure $3 \mathrm{~b}$ shows that sorting - expressed in terms of $\left(D_{50}\right)_{R M S}$ - initially increases from zero, reaches a peak and then gradually decreases for all discharges tested. However, sorting development occurs faster for larger discharges because sorting responds to spatial differences in

(a)
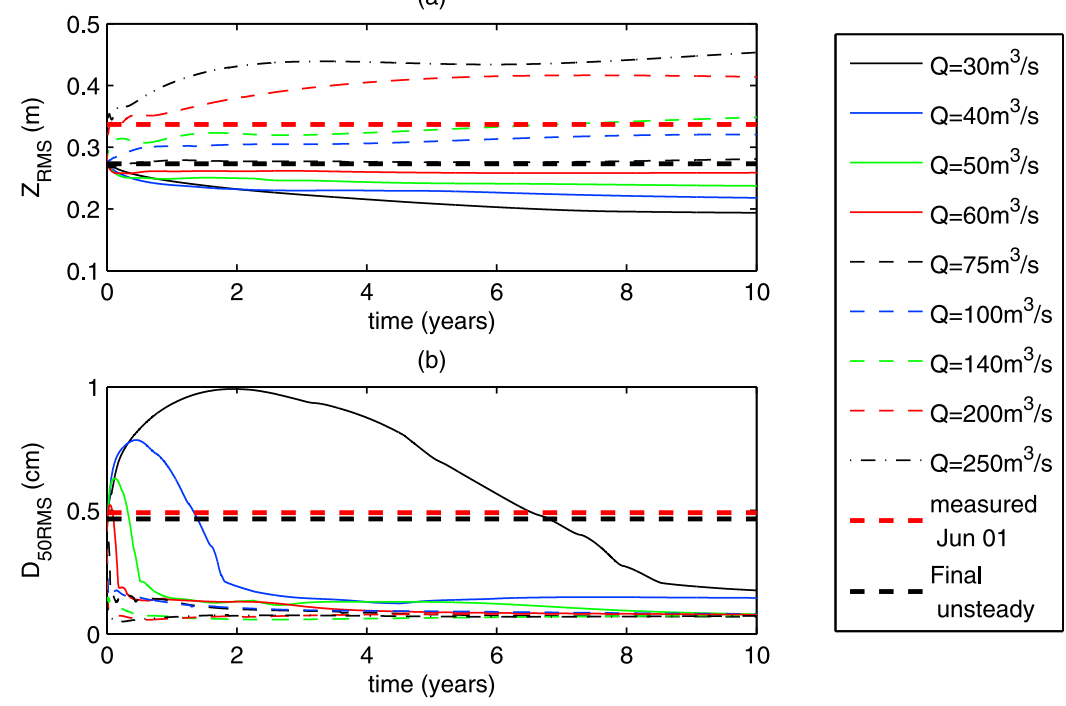

Figure 4. Time series of (a) $Z_{R M S}$ and (b) $\left(D_{50}\right)_{R M S}$ for different flow discharges for simulations beginning with the poolriffle morphology formed after the one-year variable flow simulation. Values corresponding to the bed profile in June 2001 and the final profile obtained in the variable flow simulation are also shown. 
shear stresses and, with an initially flat bed, the shear stress difference between wide and narrow cross sections is larger for larger discharges. As the pool and riffle geometry slowly develops (note that low discharges have a low transport capacity so it takes longer to make significant bed changes) shear stress differences between pools and riffles diminish and sorting is also reduced.

[19] The pool-riffle degradation experiments also show markedly distinct patterns of bed evolution as a function of flow discharge, with flows above a certain threshold increasing the disparity between pool and riffle elevations and those below the threshold gradually flattening the reach. This agrees with the early observations of Seddon [1900] and Gilbert [1914] of low discharges filling pools and eroding riffles, and high discharges doing the opposite. As with the constant flow formation experiments, the discharges that produce asymptotic values of bedform size similar to the existing in the reach varied between 75 and $140 \mathrm{~m}^{3} / \mathrm{s}$. The start-up bed conditions (elevations and grainsize distribution) used in these experiments correspond to the final results of the variable flow simulation, and thus reflect the flow history of the last months shown in Figure 1. When faced with new values of discharge (and the associated gradients of shear stress and sediment transport capacity) the reach tends to adjust its morphology and grainsize distribution in order to reduce bedload gradients. With the bedforms in place, low flows impose very high shear stress gradients between pools and riffles and the reach responds by rapidly increasing the disparity between pool and riffle grain sizes. Conversely, the higher flows are associated with shear stress gradients that are smaller than the ones that correspond to the initial morphology and as a result, a reduction in $\left(D_{50}\right)_{R M S}$ is observed initially.

[20] Results from the constant flow simulations clarify the relative importance of changes in topography and bed sediment composition as feedback mechanisms in response to changing flow conditions. Even though these two processes take place concurrently, they operate at different time scales. While a small amount of sediment erosion or deposition can produce significant changes in the bed surface grainsize distribution, bed elevation changes require relatively higher volumes of sediment mobilization and thus longer duration periods. Bed elevation changes (particularly riffle crest control) have important effects on flow conditions and shear stress redistribution both locally and in upstream reaches [Pasternack et al., 2008; de Almeida and Rodriguez, 2011]. The peaks in $\left(D_{50}\right)_{R M S}$ observed in Figures $3 \mathrm{~b}$ and $4 \mathrm{~b}$ for low discharges reflect this disparity in the time scales of the above-mentioned mechanisms. The rapid adaptation of grain sizes as a result of high shear gradients occurs in tandem with the modification of the topography, which is also adapting to reduce flow gradients but more gradually. In the long run, topography adaptation (e.g., flattening for low discharges) becomes the dominant process and grain sorting simply responds to the imposed low shear gradients by reducing sediment size differences between pools and riffles.

[21] The previous analysis of the differences in time scales allows us to put forward a new hypothesis for the formation and self maintenance of pool-riffle sequences in gravel bed streams that incorporates flow and sediment processes. In a variable flow regime high discharges occurring during flood peaks produce extreme riffle deposition and pool erosion, and rapidly equalizes grainsize distribution over the reach (see Animation S1). During the falling limb of the hydrograph shear stress gradients are restored and strong coarsening and fining takes place respectively on riffles and pools, re-establishing grainsize differences. The maintenance of this longitudinal differences in grainsize is only possible because the duration of these intermediate discharges (which concurrently erode riffle crests) is long enough for sorting but too short to produce significant flattening of the pool-riffle sequence. Flattening is also limited by armouring of riffle crests, which also occurs during the receding limb. Extreme riffle deposition and pool erosion during peak flows is thus partially restored during the falling limb of the hydrographs [see also Clifford and Richards, 1992], when riffle erosion and pool deposition take place as a consequence of higher shear stresses in the riffle. To some extent the magnitude of the flood is not that important, since the more extreme deposition and erosion events associated with higher floods will be compensated by larger corresponding flattening events.

[22] It is important to highlight that the asymptotic poolriffle morphology formed without the corresponding grain sorting characteristics usually found in natural streams is, at least in part, a result of the action of medium to high flow discharges over very long periods. This constitutes a rather idealized scenario, and is used in our analysis to achieve further insight on how pool-riffle morphodynamics is expected to respond to strong stresses. Although this scenario is unrealistic even under very aggressive flow regulation strategies, it illustrates some trends of morphodynamic evolution with a very strong physical basis.

[23] The above findings have important implications for the analysis and design of flow management strategies. In particular, reservoir operation strategies that typically increase the duration of pool-riffle destructive discharges (low to medium discharges) at the expense of a reduction in peak flows may cause significant deterioration in the morphology of the downstream reaches. The resulting degradation manifests itself not only in the loss of flow heterogeneity (e.g., velocities and depths) but also by reducing longitudinal sorting, an important requirement for a number of ecological processes.

[24] All of our simulations considered a variable channel width that did not change in time. Whether variations of channel width in a pool-riffle sequence are imposed by larger-scale processes or the result of an autogenic process connected to the development of the pool-riffle sequence itself is still an unanswered question.

[25] Acknowledgments. The Editor thanks Ellen Wohl and an anonymous reviewer for their assistance in evaluating this paper.

\section{References}

Booker, D. J., D. A. Sear, and A. J. Payne (2001), Modelling threedimensional flow structures and patterns of boundary shear stress in a natural pool-riffle sequence, Earth Surf. Processes Landforms, 26, 553-576, doi:10.1002/esp.210.

Caamaño, D., P. Goodwin, and J. M. Buffington (2012), Flow structure through pool-riffle sequences and a conceptual model for their sustainability in gravel-bed rivers, River Res. Appl., 28, 377-389, doi:10.1002/ rra. 1463 .

Clifford, N. J. (1993), Formation of riffle-pool sequences: Field evidence for an autogenetic process, Sediment. Geol., 85, 39-51, doi:10.1016/ 0037-0738(93)90074-F.

Clifford, N. J., and K. Richards (1992), The reversal hypothesis and the maintenance of riffle-pool sequences: A review and field appraisal, in 
Lowland Floodplain Rivers: Geomorphological Perspectives, edited by P. Carling and G. Petts, pp. 43-70, John Wiley, Chichester, U. K.

de Almeida, G. A. M., and J. F. Rodríguez (2011), Understanding poolriffle dynamics through continuous morphological simulations, Water Resour. Res., 47, W01502, doi:10.1029/2010WR009170.

Gilbert, G. K. (1914), Transportation of debris by running water, U.S. Geol. Surv. Prof. Pap., 86, 221 pp.

Hirano, M. (1971), River bed degradation with armoring, Proc. Jpn. Soc. Civ. Eng., 195, 55-65, doi:10.2208/jscej1969.1971.195 55.

Keller, E. A. (1971), Areal sorting of bed-load material: The hypothesis of velocity reversal, Geol. Soc. Am. Bull., 82, 753-756, doi:10.1130/00167606(1971)82[753:ASOBMT]2.0.CO;2.

MacWilliams, M. L., Jr., J. M. Wheaton, G. B. Pasternack, R. L. Street, and P. K. Kitanidis (2006), Flow convergence routing hypothesis for poolriffle maintenance in alluvial rivers, Water Resour. Res., 42, W10427, doi:10.1029/2005WR004391.

Pasternack, G. B., M. K. Bounrisavong, and K. K. Parikh (2008), Backwater control on riffle-pool hydraulics, fish habitat quality, and sediment transport regime in gravel-bed rivers, J. Hydrol., 357, 125-139, doi:10.1016/j.jhydrol.2008.05.014.

Repetto, R., M. Tubino, and C. Paola (2002), Planimetric instability of channels with variable width, J. Fluid Mech., 457, 79-109, doi:10.1017/ S0022112001007595.

Reuter, J. M., R. B. Jacobson, and C. M. Elliott (2003), Physical stream habitat dynamics in lower Bear Creek, northern Arkansas, Biol. Sci. Rep. USGS/BRD/BSR-2003-0002, 122 pp., U.S. Geol. Surv., Columbia, Mo.

Rhoads, B. L., M. H. Garcia, J. Rodríguez, F. Bombardelli, J. Abad, and M. Daniels (2008), Methods for evaluating the geomorphological performance of naturalized rivers: Examples from the Chicago metropolitan area, in Uncertainty in River Restoration, edited by D. Sears and S. Darby, pp. 209-228, John Wiley, Chichester, U. K., doi:10.1002/ 9780470867082.ch11.

Sawyer, A. M., G. B. Pasternack, H. J. Moir, and A. A. Fulton (2010), Riffle-Pool maintenance and flow convergence routing confirmed on a large gravel bed river, Geomorphology, 114, 143-160, doi:10.1016/j. geomorph.2009.06.021.
Seddon, J. A. (1900), River hydraulics, Trans. Am. Soc. Civ. Eng., 43, $1-183$.

Thompson, D. M. (2011), The velocity-reversal hypothesis revisited, Prog. Phys. Geogr., 35, 123-132, doi:10.1177/0309133310369921.

Thompson, D. M., and K. S. Hoffman (2001), Equilibrium pool dimensions and sediment-sorting patterns in coarse-grained, New England channels, Geomorphology, 38, 301-316, doi:10.1016/S0169-555X(00)00100-8.

Thompson, D. M., and E. E. Wohl (2009), The linkage between velocity patterns and sediment entrainment in a forced-pool and riffle unit, Earth Surf. Processes Landforms, 34, 177-192, doi:10.1002/esp.1698.

Thompson, D. M., E. E. Wohl, and R. D. Jarrett (1996), A revised velocityreversal and sediment-sorting model for a high-gradient, pool-riffle stream, Phys. Geogr., 17, 142-156.

Thompson, D. M., E. E. Wohl, and R. D. Jarret (1999), Velocity reversals and sediment sorting in pools and riffles controlled by channel constrictions, Geomorphology, 27, 229-241, doi:10.1016/S0169-555X(98) 00082-8.

Tubino, M., and G. Seminara (1990), Free-forced interactions in developing meanders and suppression of free bars, J. Fluid Mech., 214, 131-159, doi:10.1017/S0022112090000088.

White, J. Q., G. B. Pasternack, and H. J. Moir (2010), Valley width variation influences riffle-pool location and persistence on a rapidly incising gravel-bed river, Geomorphology, 121, 206-221, doi:10.1016/j. geomorph.2010.04.012.

Wilcock, P. R., and J. C. Crowe (2003), Surface-based transport model for mixed-size sediment, J. Hydraul. Eng., 129, 120-128, doi:10.1061/ (ASCE) 0733-9429(2003)129:2(120).

Yang, C. T. (1971), Formation of riffles and pools, Water Resour. Res., 7, 1567-1574, doi:10.1029/WR007i006p01567.

G. A. M. de Almeida, School of Geographical Sciences, University of Bristol, University Road, Bristol BS8 1SS, UK. (gustavo.dealmeida@ bristol.ac.uk)

J. F. Rodríguez, School of Engineering, University of Newcastle Australia, University Drive, Callaghan, NSW 2308, Australia. 